\title{
Pengaruh Peran Kepala Madrasah Sebagai Manajer dan Supervisor Terhadap Profesionalisme Guru MA Al Amiriyyah Blokagung Banyuwangi
}

\author{
Komarudin A. ${ }^{1}$, Vivi Indah Lestari \\ e-mail: komarudin@iaida.ac.id ${ }^{1}$,Viviindah839@gmail.com² \\ Manajemen Pendidikan Islam \\ Institut Agama Islam Darussalam Blokagung Banyuwangi
}

\begin{abstract}
This research is directed at 3 main points, namely (1) is there an influence on the role of the madrasa head as manager on the professionalism of MA Al Amiriyyah Blokagung Tegalsari Banyuwangi 2019/2020 academic year (2) is there any influence on the role of the madrasah head as supervisor on the professionalism of MA Al Amiriyyah Blokagung teachers Tegalsari Banyuwangi 2019/2020 academic year (3) is there any influence of the role of the madrasa head as manager and supervisor on the professionalism of MA Al Amiriyyah Blokagung teachers Tegalsari Banyuwangi 2019/2020 academic year. This study uses quantitative methods with product moment techniques in the validity of the data and to find the reliability of the data using the alpha formula, while in the hypothesis test using the $F$ test and $P$ test then using multiple regression models. The population of this study was 40 Al Amiriyyah MA teachers. To measure variables, researchers use questionnaires for facilities and infrastructure and teacher performance. After analyzing the data collected, it was found that (1) the role of the madrasa head as a manager did not affect the professionalism of MA AL Amiriyyah Blokagung Tegalsari Banyuwangi teacher year 2019/2020. (2) the role of the madrasa head as a supervisor affects the professionalism of the MA AL Amiriyyah Blokagung Tegalsari Banyuwangi teacher in the 2019/2020 academic year. (3) factors influencing the professionalism of MA Al Amiriyyah Blokagung Tegalsari banyuwangi teachers are only the role of the madrasah head as supervisor.
\end{abstract}

Key words: Manager, Supervisor, Teacher Professionalism

\begin{abstract}
Abstrak
Penelitian ini diarahkan pada 3 hal pokok, yaitu (1) adakah pengaruh peran kepala madrasah sebagai manajer terhadap profesionalisme guru MA Al Amiriyyah Blokagung Tegalsari Banyuwangi tahun pembelajaran 2019/2020 (2) adakah pengaruh peran kepala madrasah sebagai supervisor terhadap profesionalisme guru MA Al Amiriyyah Blokagung Tegalsari Banyuwangi tahun pembelajaran 2019/2020 (3) adakah pengaruh peran kepala madrasah sebagai manajer dan supervisor terhadap profesionalisme guru MA Al Amiriyyah Blokagung Tegalsari Banyuwangi tahun pembelajaran 2019/2020. Penelitian ini

Pengaruh Peran Kepala Madrasah Sebagai Manajer dan Supervisor Terhadap Profesionalisme Guru MA Al Amiriyyah Blokagung Banyuwangi

Komarudin A., Vivi Indah Lestari
\end{abstract}


JMPID ( Jurnal Manajemen Pendidikan Islam Darussalam )

Jurnal Manajemen Pendidikan Islam

Volume: 2, No: 2, September 2020

ISSN : 2722-7146 (online)

menggunakan metode kuantitatif dengan teknik konsultasi dengan dosen ahli pada uji validitas data dan untuk mencari reliabilitas data menggunakan rumus alpha, sedangkan pada uji hipotesis menggunakan uji $F$ dan uji $P$ kemudian menggunakan model regresi ganda. Populasi penelitian ini adalah guru MA Al Amiriyyah yang berjumlah 40 orang. Untuk mengukur variabel, peneliti menggunakan kuesioner untuk peran kepala madrasah sebagai manajer dan supervisor serta profesionalisme guru. Setelah melakukan analisis data yang dikumpulkan, ditemukan bahwa (1) peran kepala madrasah sebagai manajer tidak mempengaruhi profesionalisme guru MA AL Amiriyyah Blokagung Tegalsari Banyuwangi tahun pembelajaran 2019/2020. (2) peran kepala madrasah sebagai supervisor mempengaruhi profesionalisme guru MA AL Amiriyyah Blokagung Tegalsari Banyuwangi tahun pembelajaran 2019/2020. (3) fakor yang mempengaruhi profesionalisme guru MA Al Amiriyyah Blokagung Tegalsari banyuwangi hanya peran kepala madrasah sebagai supervisor.

Kata-kata kunci : Manajer, Supervisor, Profesionalisme Guru

\section{A. Pendahuluan}

\section{Latar belakang}

Peningkatan kualitas sember daya manusia (SDM) bisa dicapai melalui dunia pendidikan. Kegiatan pendidikan dilaksanakan leh sekolah/madrasah yang dipimpin oleh kepala madrasah/sekolah. Menjadi kepala madrasah memiliki tanggung jawab besar untuk menyelenggarakan kegiatan madrasah secara efektif, sehingga kemajuan madrasah bergabtung pada kepemimpinan kepala madrasah.

Peran kepala madrasah sebagai manajer sangat dibutuhkan. Karena dalam peran menjadi manajer sangat dibutuhkan dalam mendayagunakan sumber daya yang dikaitkan dalam perencanaan, pengembangan kurikulum dan pembelajaran, pengelolaan ketanagaan, sarana dan sumber belajar, dan evaluasi program madrasah. Kepala madrasah juga dituntut untuk menciptakan situasi kerja yang kondusif, sehingga peran kepala madrasah sebagai manajer memiliki kontribusi yang kuat dalam meningkatkan profesionalisme guru.

Kepala madrasah juga memiliki peran sebagai supervisor dalam meningkatkan profesionalisme guru. Supervisi memiliki kegiatan pokok seperti pembinaan yang terus menerus, pengembangan profesional personil, perbaikan kegiatan pembelajaran dengan sasaran akhir percapaian tujuan Pengaruh Peran Kepala Madrasah Sebagai Manajer dan Supervisor Terhadap Profesionalisme Guru MA Al Amiriyyah Blokagung Banyuwangi

Komarudin A., Vivi Indah Lestari 
JMPID ( Jurnal Manajemen Pendidikan Islam Darussalam )

Jurnal Manajemen Pendidikan Islam

pendidikan dan pertumbuhan peserta didik. Sehingga kepala madrasah memiliki peran sebagai mensupervisi proses pebelajaran di madrasah setiap hari yang memiliki tujuan perbaikan mutu kinerja guru dalam menjalankan tugasnya yang direalisasikan dalam pembelajaran yang efektif.

Guru menjadi garda terdepan dalam dunia pendidikan. Guru menjadi pelaku utama dalam proses pembelajaran. Maka dari itu kualitas pendidikan tergantung oleh profesionalisme guru. Guru menjadi agen pembelajaran dan motivator bagi peserta didik. Peserta didik menerima pengetahuan melalui proses pembelajaran bersama guru. Dari sini guru dituntut untuk terus meningkatkan sikap profesional dalam mencapai tujuan madrasah dan tujuan pendidikan.

MA Al Amiriyyah adalah salah satu Madrasah Aliyah yang memiliki program IPA dan Agama Unggulan di Banyuwangi. Hali ini dibuktikan dengan paparan data dari Kemendikbud Kabupaten Banyuwangi. Selain itu berdasarkan observasi banyak ditemukan babeberapa kegiatan yang berhubungan dengan peran kepala madrasah sebagai manajer dan supervisor dalam meningkatkan profesionalisme guru. Sehungga peneliti tertarik untuk mengajukan judul penelitian "Pengaruh Peran Kepala Madrasah Sebagai Manajer dan Supervisor dalam Meningkatkan Profesionalisme Guru MA Al Amiriyyah Blokagung Tegalsari Banyuwangi Tahun Pembelajran 2019/2020.

\section{Rumusan Masalah}

Dari indentifikasi masalah yang ada peneliti memiliki rumusan masalah sebagai berikut:

a. Adakah Pengaruh peran Kepala Madrasah sebagai Manajer terhadap Profesionalisme Guru di MA Al Amiriyyah Blokagung Tegalsari Banyuwangi Tahun Pembelajaran 2019/2020?

b. Adakah Pengaruh peran Kepala Madrasah sebagai Supervisor terhadap Profesionalisme Guru di MA Al Amiriyyah Blokagung Tegalsari Banyuwangi Tahun Pembelajaran 2019/2020?

Pengaruh Peran Kepala Madrasah Sebagai Manajer dan Supervisor Terhadap Profesionalisme Guru MA Al Amiriyyah Blokagung Banyuwangi

Komarudin A., Vivi Indah Lestari 
JMPID ( Jurnal Manajemen Pendidikan Islam Darussalam )

Jurnal Manajemen Pendidikan Islam

c. Adakah Pengaruh peran Kepala Madrasah sebagai Manajer dan Supervisor terhadap Profesionalisme Guru MA Al Amiriyyah Blokagung Tegalsari Banyuwangi Tahun Pembelajaran 2019/2020?

\section{Manfaat Penelitian}

Hasil penelitian diharapkan bermanfaat untuk:

a. Secara teoritis

1) Menambah pengetahuan tentang peran kepala madrasah sebagai manajer

2) Menambah pengetahuan tentang peran kepala madarsah sebagai supervisor

3) Menambah pengetahuan tentang proesionalisme guru

b. Secara Praktis

1) Sebagai saran untuk dijadikan pedoman lembaga

2) Sebagai cerminan untuk mengembangkan lembaga

\section{B. Landasan Teori}

\section{Peran Kepala Madrasah Sebagai Manajer}

Dalam Maulida (2016:10) mengutip pendapat dari Mulyasa (2006) mendefinisikan "Peran sebagai bentuk rangkaian ucapan, tindakan, perasaan, sebagai bentuk gambar hubungan yang menarik yang diajukan oleh individu terhadap lainnya." Maulida juga mengutip Pendapat dari Soekanto (2009) menjelaskan bahwa "Peran adalah proses dinamis yang melaksanakan kewajiban sesuai dengan kedudukannya." Jadi, peran adalah suatu proses rangkaian ucapan, tindakan, dan perasaan yang dinamis untuk menjalankan kewajiban sesuai dengan kedudukannya.

Menurut Permendiknas Nomor 28 tahun 2010 tentang penugasan guru sebagai kepala sekolah/ madrasah adalah "Guru yang diberi tugas tambahan untuk memimpin sekolah atau madrasah." Hal ini senada dengan pendapat yang dikemukakan oleh Daryanto (2008) kepala sekolah/madrasah pemegang tanggung jawab dalam penyelenggaraan seluruh kegiatan di sekolah/madrasah. Jadi kepala madrasah adalah guru 
JMPID ( Jurnal Manajemen Pendidikan Islam Darussalam )

Jurnal Manajemen Pendidikan Islam

yang merangkap memimpin madrasah yang memiliki tanggung jawab penuh dalam pelaksanaan seluruh kegiatan di Lingkungan sekolah/madrasah.

Syarat-syarat Kepala Sekolah/Madrasah menurut Permendiknas No. 28 tahun 2010 tentang kepala sekolah/madrasah adakalanya syarat umum dan syarat khusus.

1) Syarat umum

a) Beriman dan bertaqwa kepada Tuhan YME

b) Memiliki kualifikasi paling rendah sarjana (S1) atau diploma empat (D-IV) kependidikan

c) Berusia maksimal 56 tahun

d) Sehat jasmani rohani berdasarkan surat keterangan dari dokter Pemerintah

e) Tidak pernah dikenakan hukuman disiplin

f) Memiliki sertifikat pendidik

g) Pengalaman mengajar minimal 5 tahun menurut jenis dan jenjang sekolah/madrasah

h) Memiliki golongan ruang minimal III/c bagi guru pegawai negeri sipil (PNS) dan bagi guru bukan PNS disetarakan dengan kepangkatan yang dikeluarkan oleh yayasan atau lembaga yang berwenang dibuktikan dengan SK inpasing

i) Memperoleh nilai amat baik untuk unsur kesetiaan dan nilai baik untuk unsur penilaian lainnya sebagai guru dalam daftar penilaian prestasi pegawai (DP3) dan PNS atau penilaian yang sejenis DP3 bagi bukan PNS dalam dua tahun terakhir

j) Memperoleh nilai baik untuk penilaian kinerja sebagai guru dalam dua tahun terakhir

2) Syarat khusus

a) Berstatus sebagai guru pada jenis atau jenjang sekolah/madrasah yang sesuai

Pengaruh Peran Kepala Madrasah Sebagai Manajer dan Supervisor Terhadap Profesionalisme Guru MA Al Amiriyyah Blokagung Banyuwangi

Komarudin A., Vivi Indah Lestari 
JMPID ( Jurnal Manajemen Pendidikan Islam Darussalam )

Jurnal Manajemen Pendidikan Islam

Volume: 2, No: 2, September 2020

ISSN : 2722-7146 (online)

b) Memiliki sertifikat kepala sekolah/madrasah pada jenis dan jenjang yang sesuai dengan pengalamannya

Menurut Permendiknas pasal 19 tahun 2017 “Tugas pokok kepala sekolah/madrasah sepenuhnya untuk melaksanakan tugas manajerial, pengembangan kewirausahaan, dan supervisi kepada guru dan tenaga kependidikan." Melihat keterangan Permendiknas kepala sekolah/madrasah harus menguasai manajerial. Menurut Arifin dalam Maulida (2016:25) fungsi kepala sekolah/madrasah sebagai manajer yaitu mengelola semua sumber daya yang dimiliki sekolah untuk dapat berjalan secara efektif dan efesien. Kompetensi manajerial kepala madrasah/sekolah sesuai dengan Permendiknas Nomor 13 Tahun 2007 tentang standar Kepala Madrasah/Sekolah yaitu:

1) Menyusun perencanaan madrasah/sekolah untuk berbagai tingkatan perencanaan

2) Mengembangkan organisasi madrasah/sekolah sesuai dengan kebutuhan

3) Memimpin madrasah/sekolah dalam rangka mendayagunakan sumber daya madrasah/sekolah secara optimal

4) Mengelola perubahan dan perkembangan madrasah/sekolah menuju organisasi pembelajaran yang efektif

5) Menciptakan budaya dan iklim madrasah/sekolah yang kondusif dan inovatif bagi pembelajaran peserta didik

6) Mengelola guru dan staf dalam rangka pendayagunaan sumber daya manusia secara optimal

7) Mengelola sarana dan prasarana madrasah/sekolah dalam rangka mendayagunakan secara optimal

8) Mengelola hubungan masyarakat dan sekolah/madrasah dalam rangka pencarian dukungan ide, sumber belajar dan pembiayaan madrasah/sekolah

Pengaruh Peran Kepala Madrasah Sebagai Manajer dan Supervisor Terhadap Profesionalisme Guru MA Al Amiriyyah Blokagung Banyuwangi

Komarudin A., Vivi Indah Lestari 
JMPID ( Jurnal Manajemen Pendidikan Islam Darussalam )

Jurnal Manajemen Pendidikan Islam

9) Mengelola peserta didik dalam rangka penerimaan peserta didik baru, dan penempatan serta pengembangan kapasitas peserta didik

10) Mengelola pengembangan kurikulum dan kegiatan pembelajaran sesuai dengan arah dan tujuan pendidikan nasional

11) Mengelola keuangan madrasah/sekolah sesuai dengan prinsip pengelolaan, akutanbel, trasparan, dan efisien

12) Mengelola ketatausahaan madrasah/sekolah dalam mendukung pencapaian tujuan madrasah/sekolah

13) Mengelola unit layanan khusus madrasah/sekolah dalam mendukung kegiatan pembelajaran dan kegiatan peserta didik di madrasah/sekolah

14) Mengelola sistem informasi madrasah/sekolah dalam mendukung penyusunan program dan pengambilan keputusan. Memanfaatkan kemajuan teknologi informasi bagi peningkatan pembelajaran dan manajemen sekolah/madrasah.

15) Melakukan monitoring, evaluasi dan pelaporan pelaksanaan program kegiatan madrasah/sekolah dengan prosedur yang tepat serta merencanakan tindak lanjut.

Kepala sekolah/madrasah memiliki beberapa fungsi manajerial menurut Suryosubroto (2004) dalam Setiadi (2013:28) menjelaskan fungsi kepala madrasah sebagai manajer, seperti:

1) Merencanakan

2) Mengorganisasikan

3) Mengordinasikan

4) Melaksanakan

Pengaruh Peran Kepala Madrasah Sebagai Manajer dan Supervisor Terhadap Profesionalisme Guru MA Al Amiriyyah Blokagung Banyuwangi

Komarudin A., Vivi Indah Lestari 
JMPID ( Jurnal Manajemen Pendidikan Islam Darussalam )

Jurnal Manajemen Pendidikan Islam

Volume: 2, No: 2, September 2020

ISSN : 2722-7146 (online)

\section{Peran Kepala Madrasah Sebagai Supervisor}

Supervisi secara bahasa berasal dari kata super dan visi yang bermakna melihat, dan meninjau dari atas atau menilik dan menilai dari atas yang dilakukan oleh pihak atasan terhadap aktivitas, kreativitas, dan kinerja bawahan. Supervisi memiliki beberapa istilah yaitu: pengawasan yang bermaksud kegiatan untuk melakukan pengamatan agar pekerjaan sesuai dengan ketentuan, pemeriksaan bermaksud melihat bagaimana kegiatan telah mencapai tujuan, dan inspeksi bermaksud kegiatan untuk mengetahui kekurangan.

Sesuai dengan Permendiknas yang sudah dijelaskan pada peran kepala madrasah sebagai manajer, kepala madrasah/sekolah juga harus memiliki kompetensi supervisi. Supervisi dalam Wahyudin (2014:206) menyimpulkan dari pendapat Mulyasa (2009) merupakan "Proses yang dibentuk dengan khusus untuk membantu para guru dan supervisor dalam mempelajari tugas harianya di madrasah agar dapat memberikan pelayanan kepada orang tua peserta didik dan madrasah/sekolah, serta menjadikan madrasah/sekolah sebagai masyarakat yang belajar secara efektif."

Dari beberapa definisi di atas supervisi memuat beberapa kegiatan utama yaitu: pembinaan yang Continue, pengembangan kemampuan profesional personil, perbaikan situasi belajar-mengajar, dengan sasaran pencapaian tujuan pendidikan dan pertumbuhan pribadi peserta didik. Lebih singkatnya bahwa supervisi adalah kegiatan pengawasan dan pengendalian yang dilakukan guna meningkatkan profesional guru. Jadi, supervisi adalah rangkaian pengawasan dan pengendalian yang dibentuk khusus dalam rangka membantu guru dalam meningkatkan profesional dalam melayani dan menjadikan sekolah/madrsah sebagai masyarakat belajar yang efektif. Secara umum supervisi memiliki tujuan mengembangkan iklim yang kondusif dan lebih baik dalam kegiatan belajar-mengajar, melalui Pengaruh Peran Kepala Madrasah Sebagai Manajer dan Supervisor Terhadap Profesionalisme Guru MA Al Amiriyyah Blokagung Banyuwangi

Komarudin A., Vivi Indah Lestari 
JMPID ( Jurnal Manajemen Pendidikan Islam Darussalam )

Jurnal Manajemen Pendidikan Islam

pembinaan dan peningkatan profesi mengajar guna mewujudkan tujuan belajar peserta didik.

Pelaku supervisi di sekolah/madrasah adalah kepala sekolah/madrasah. Kepala sekolah/madrasah yang melakukan supervisi harus mampu melakukan berbagai pengawasan dan pengendalian untuk meningkatkan kinerja tenaga pendidik dan kependidikan sebagai bentuk pengontrolan kegiatan sekolah/madarsah agar terarah pada tujuan yang telah ditentukan. Dalam Permendiknas No. 13 tahun 2007 "Kompetensi supervisi kepala sekolah/madrasah yaitu:

a) Merencanakan program supervisi akademik dalam rangka meningkatkan profesional guru. Dalam Priansa dan Setiana (2018:249-250) mengutip pendapat Thalib (2005) "Supervisor harus menyusun perencanaan supervisi yaitu:

1) Daftar lengkap sekolah dan guru yang berada di wilayah kepengawasan

2) Kegiatan tahunan, bulanan, dan mingguan

3) Jadwal kunjungan sekolah

4) Jadwal kunjungan kelas"

b) Melaksanakan supervisi akademik terhadap guru dengan menggunakan pendekatan dan teknik supervisi yang tepat. Priansa dan Setiana (2018:251-252) sesuai dengan Buku Panduan Depdiknas (2010) kegiatan yang perlu dilakukan kepala madrasah sebagai supervisor antara lain:

1) Memahami konsep, prinsip, teori dasar, karakteristik dan kecenderungan perkembangan tiap bidang pengembangan pembelajaran kreatif, inovatif, pemecahan masalah, berpikir kritis, dan naluri kewirausahaan

Pengaruh Peran Kepala Madrasah Sebagai Manajer dan Supervisor Terhadap Profesionalisme Guru MA Al Amiriyyah Blokagung Banyuwangi

Komarudin A., Vivi Indah Lestari 
JMPID ( Jurnal Manajemen Pendidikan Islam Darussalam )

Jurnal Manajemen Pendidikan Islam

2) Membimbing guru dalam menyusun silabus tiap bidang pengembangan di sekolah atau mata pelajaran di sekolah berlandaskan standar isi, standar kompetensi dan kompetensi dasar, serta prinsip-prinsip pengembangan kurikulum

3) Membimbing guru dalam memilih dan menggunakan strategi/metode/teknik pembelajaran/ bimbingan yang dapat mengembangkan berbagai potensi peserta didik

4) Membimbing guru dalam melaksanakan kegiatan pembelajaran/bimbingan (di kelas, laboratorium dan lapangan) untuk mengembangkan potensi peserta didik

5) Membimbing gruru dalam mengelola, merawat, mengembangkan, dan menggunakan media pendidikan dan fasilitas pembelajaran

6) Memotivasi guru untuk memanfaatkan teknologi informasi untuk pembelajaran

c) Menindaklanjuti hasil supervisi akademik terhadap guru dalam rangka meningkatkan profesionalisme guru. Priansa dan Setiana (2018:255) bahwa "Tindak lanjut dari supevisi dalam bentuk penghargaan dan penguatan, teguran yang bersifat mendidik, dan kesempatan untuk mengikuti pelatihan lebih lanjut."

Pada prinsipnya pelaksanaan supervisi harus dilakukan pada tenaga pendidik secara periodik dalam pelaksanaan tugasnya. Pelaksanaan supervisi dalam Wahyudin (2014:206) dapat dilakukan dengan cara sebagai berikut:

a) Diskusi kelompok

Pengaruh Peran Kepala Madrasah Sebagai Manajer dan Supervisor Terhadap Profesionalisme Guru MA Al Amiriyyah Blokagung Banyuwangi

Komarudin A., Vivi Indah Lestari 
JMPID ( Jurnal Manajemen Pendidikan Islam Darussalam )

Jurnal Manajemen Pendidikan Islam

b) Pembicaraan individual

c) Kunjungan dan observasi kelas

d) Simulasi pembelajaran

e) Perpustakaan profesional

Pelaksanaan supervisi yang berhasil dapat dinilai melalui kesadaran tenaga pendidik dalam meningkatkan kinerja dan keterampilan dalam pelaksanaan tugasnya.

\section{Profesionalisme Guru}

Dalam Karwati dan Priansa (2015) "Profesionalisme merujuk pada komitmen anggota-anggota profesi dalam meningkatkan kemampuan profesionalnya dan mengembangkan secara terus menerus strategi yang digunakan dalam melaksanakan tugas yang sesuai dengan profesinya." Jadi, profesionalisme komitmen anggota profesi dalam meningkatkan mutu profesionalnya.

Guru dalam Undang-Undang RI Nomor 14 tahun 2005 tentang guru dan dosen adalah "Pendidik profesional dengan tugas utama mendidik, mengajar, membimbing, mengarahkan, melatih, menilai, dan mengevaluasi peserta didik pada pendidikan anak usia dini jalur pendidikan formal, pendidikan dasar, dan pendidikan menengah." Secara luas profesionalisme menunjukan pada seseorang yang memiliki sifat ahli atau terampil dalam seni atau aktivitas tertentu. Jadi profesionalisme guru adalah keahlian yang dimiliki oleh guru dalam proses pembelajaran.

Hamalik (2006: 27) "Guru profesional adalah orang yang telah menempuh program pendidikan guru dan tingkat master serta telah mendapat ijazah negara dan telah berpengalaman dalam mengajar pada kelas-kelas besar." Tugas guru mengutip dari Undang-undang Nomor 20 Tahun 2003 menjelaskan bahwa "Tugas guru adalah merencanakan, Pengaruh Peran Kepala Madrasah Sebagai Manajer dan Supervisor Terhadap Profesionalisme Guru MA Al Amiriyyah Blokagung Banyuwangi

Komarudin A., Vivi Indah Lestari 
JMPID ( Jurnal Manajemen Pendidikan Islam Darussalam )

Jurnal Manajemen Pendidikan Islam

dan melaksanakan proses pembelajaran, menilai hasil pembelajaran, melakukan pembimbingan dan pelatihan." Guru diharapkan dapat melaksanakan tugas keprofesionalnya dengan baik. Guru yang memiliki rasa profesionalisme bekerja sesuai kompetensi. Menurut Arifin dalam Maswan dan Muslimin (2017:360) menyatakan bahwa profesi dan kompetensi memiliki hubungan yang erat yaitu kompetensi tanpa profesi akan kehilangan guna dan profesi tanpa kompetensi akan kehilangan makna. Oleh karena itu Mulyasa (2008: 75) menjelaskan kompetensi profesionalisme guru yang senada dengan UU No. 14 Tahun 2005 ada 4 aspek:

a. Kompetensi pedagogik

Dalam standar pendidikan nasional penjelasan pasar 28 ayat 3 "Kompetensi pedagogik adalah kemampuan mengelola pembelajaran peserta didik yang meliputi pemahaman terhadap peserta didik, perencanaan dan pelaksanaan pembelajaran, evaluasi hasil belajar, dan pengembangan peserta didik untuk mengaktualisasikan berbagi potensi yang dimilikinya.

b. Kompetensi kepribadian

Kemampuan kepribadian yang mantap, stabil, dewasa, arif, dan berwibawa, menjadi teladan bagi peserta didik dan berakhlak mulia. Dalam Standar Pendidikan Nasional pasal 28 ayat $3 \mathrm{~b}$ dijelaskan bahwa seorang "Guru harus memiliki sikap kepribadian yang mantap, sehingga bisa dijadikan inspirasi oleh peserta didik."

c. Kompetensi profesional

Kemampuan penguasaan materi pembelajaran secara luas dan mendalam yang memungkinkan membimbing peserta didik memenuhi standar kompetensi yang ditetapkan dalam standar nasional pendidikan. Standar Pendidik Nasional pasal 28 ayat $3 \mathrm{c}$ menjelaskan bahwa seorang "Guru harus mampu mengetahui secara luas yang berhubungan dengan bidang study

Pengaruh Peran Kepala Madrasah Sebagai Manajer dan Supervisor Terhadap Profesionalisme Guru MA Al Amiriyyah Blokagung Banyuwangi

Komarudin A., Vivi Indah Lestari 
atau subjek matter yang akan diajarkan serta penguasaan didaktik metodik dalam arti memiliki pengetahuan konsep teoritik, mampu memilih model, strategi, dan metode yang tepat serta mampu menerapkannya dalam pembelajaran.”

d. Kompetensi sosial

Kompetensi sosial adalah kemampuan guru sebagai bagian dari masyarakat untuk berkomunikasi dan bergaul secara efektif dengan peserta didik, sesama pendidik dan masyarakat sekitar. Standar Nasional Pendidikan pasal 3d menjelaskan bahwa seorang "Guru harus mampu berkomunikasi sosial yang baik dengan peserta didik, rekan kerja, kepala sekolah, maupun masyarakat luas.”

Guru yang profesional dapat dibuktikan dengan kompetensi yang dimiliki dalam meningkatkan kualitasnya agar dapat menunjang peningkatan kualitas pendidikan.

Menurut Wahyudin (2014:203) "Profesionalisme guru dapat ditingkatkan melalui dua aspek, yaitu kemampuan dan kemauan." Guru yang memiliki rasa profesional adalah guru yang memiliki kemampuan dan kemauan yang baik dalam menjalankan tugas. Oleh karena itu, untuk meningkatkan profesionalisme guru perlu adanya dukungan dengan kemampuan dan kemauan yang baik. Dari keterangan ini peran kepala madrash/sekolah sebagai manajer dan supervisor diperlukan.

Melihat hasil penelitian peran kepala sekolah sangat diperlukan dalam meningkatkan profesionalisme guru. Berikut gambaran kontribusi peran kepala madrasah dalam meningkatkan profesionalisme guru menurut Wahyudin (2014:204).

Pengaruh Peran Kepala Madrasah Sebagai Manajer dan Supervisor Terhadap Profesionalisme Guru MA Al Amiriyyah Blokagung Banyuwangi

Komarudin A., Vivi Indah Lestari 


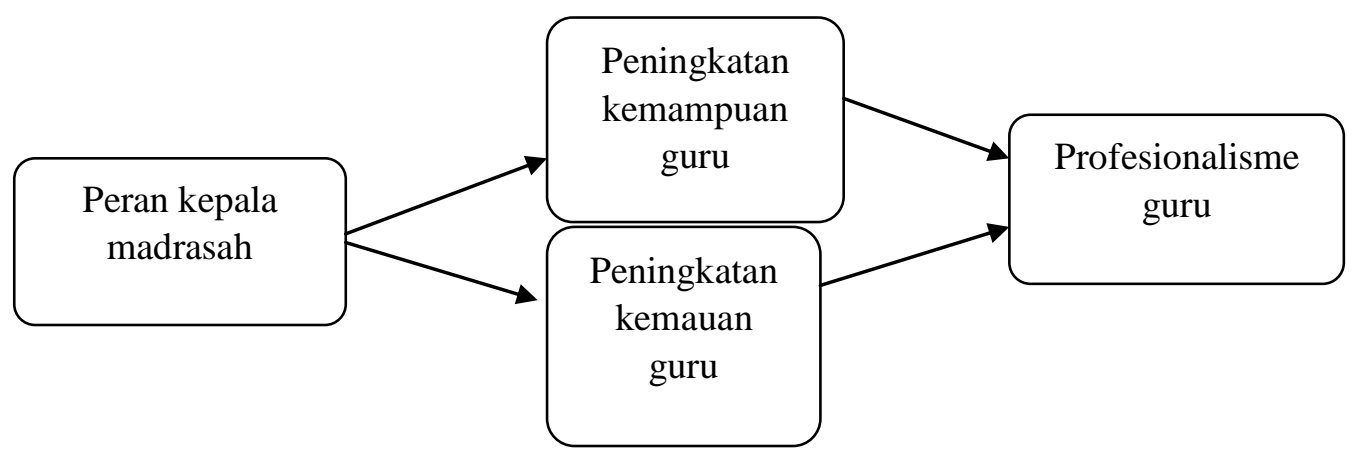

Gambar 2.1 Proses Peningkatan Profesionalisme Guru

\section{Sumber: Wahyudin (2014:204)}

Berdasarkan gambar di atas dapat menjelaskan bahwa peran kepala madrasah menjadi faktor utama dalam peningkatan profesionalisme guru. Dengan meningkatnya profesionalisme guru dalam menjalankan tugasnya, maka akan menjadi sarana tercapainya keefektifan keja organisasi madrasah yang secara langsung menunjang tercapainnya tujuan pendidikan secara optimal.

Dari keterangan ini dapat disimpulkan bahwa peran kepala madrasah sebagai manajer dalam menciptakan iklim kerja yang kondusif bisa meningkatkan profesionalisme guru di sekolah yang dipimpin. Kepala Madrasah harus menciptakan situasi dan kondisi yang dapat meningkatkan profesionalisme guru. Sehingga peran kepala madrasah sebagai manajer menjadi kunci penigkatan profesionalisme guru dan sebagai jalan menuju tercapainya keefektifan kerja madrasah. Hasil penelitian oleh Maulida (2016:85) kepala sekolah memiliki peran sebagai manajer dalam peningkatan profesionalisme guru melalui cara menciptakan iklim kerja yang kondusif, memberikan pelayanan bagi guru dalam memecahkan masalah yang dihadapi, dan mendayagunakan sumber daya yang dimiliki sekolah.

Selain peran sebagai manajer, peran kepala madrasah sebagai supervisor juga mempengaruhi peningkatan profesionalisme guru. 
JMPID ( Jurnal Manajemen Pendidikan Islam Darussalam )

Jurnal Manajemen Pendidikan Islam

Volume: 2, No: 2, September 2020

ISSN : 2722-7146 (online)

Bisa dilihat dari hakikat supervisi sendiri yang bermakna pengawasan dan pengendalian yang dilakukan dengan tujuan membantu guru. Dalam supervisi menurut Mulyasa (2017:156) "Memuat ide-ide pokok, seperti menggalakan peningkatan profesionalisme guru, mengembangkan kepemimpinan demokratis, melepaskan energi, memecahkan beberapa masalah pendidikan dan pengajaran secara efektif dan efesien." Hasil penelitian yang dilakukan oleh Syafirna (2018) menunjukan bahwa "Peran kepala madrasah memiliki peran sebagai supervisor dalam meningkatkan proesionalisme guru melalui teknik secara individual ataupun kelompok." Maka dari itu supervisi memiliki proses pelayanan dan pembinaan dalam rangka membantu guru untuk meningkatkan profesionalisme yang kemudian berdampak pada proses pembelajaran yang selanjutnya meningkatkan pertumbuhan peserta didik.

\section{Metode Penelitian}

Penelitian ini adalah penelitian kuantitatif. Tempat penelitian di MA Al Amiriyyah Blokagung Tegalsari Banyuwangi tahun pembelajaran 2019/2020. Karena populasi kurang dari 100 maka penelitian ini bersifat penelitian populasi yaitu 40. Sumber data berupa data primer dan data sekunder. Teknik pengumpulan data menggunakan kuisoner, dokumentasi dan juga observasi. Validitas melalui konsulatsi dengan 3 dosen ahli. Reliabelitas menggunakan rumus Alpha Cronbach. Analisis data menggunakan teknik analisis regresi ganda.

\section{Pembahasan}

1. Pengaruh Peran Kepala Madrasah Sebagai Manajer (X1)

Berdasarkan perolehan data dari responden menghasilkan nilai $\mathrm{T}$ Hitung 0,150 yang mana $\mathrm{T}$ hitung $<\mathrm{T}$ tabel. Maka peran kepala madrasah sebagai manajer tidak mempengaruhi profesionalisme guru

Pengaruh Peran Kepala Madrasah Sebagai Manajer dan Supervisor Terhadap Profesionalisme Guru MA Al Amiriyyah Blokagung Banyuwangi

Komarudin A., Vivi Indah Lestari 
JMPID ( Jurnal Manajemen Pendidikan Islam Darussalam )

Jurnal Manajemen Pendidikan Islam

Volume: 2, No: 2, September 2020

ISSN : 2722-7146 (online)

MA Al Amiriyyah Blokagung Tegalsari banyuwangi Tahun Pembelajaran 2019/2020.

2. Pengaruh Peran Kepala Madrasah Sebagai Supervisor (X2)

Berdasarkan perolehan data dari responden menghasilkan nilai $\mathrm{T}$ hitung 2,123 yang mana $\mathrm{T}$ hitung > $\mathrm{T}$ tabel. Hal ini berarti bahwa peran kepala Madrasah sebagai Supervisor mempengaruhi Profesinalisme guru.

3. Berdasarkan data yang diperoleh menunjukan bahwa peran kepala madrasah sebagai manajer tidak mempengaruhi profesionalisme guru dan peran kepala madrasah sebagai supervisor mempengaruhi pofesionalisme guru MA Al Amiriyyah Blokagung Tegalsari Banyuwangi Tahun Pembelajaran 2019/2020. Hasil penelitian menunjukan bahwa pengaruh peran kepala madrasah sebagai manajer dan supervisor terhadap profesionalisme guru sebesar $61,9 \%$.

\section{E. Kesimpulan}

Berdasarkan penelitian dan analisis data pada BAB sebelumnya menunjukan bahwa:

1. Berdasarkan hasil angket variabel $\mathrm{X} 1$ menunjukan bahwa peran kepala madrasah sebagai manajer tidak mempengaruhi profesionalisme guru

2. Berdasarkan hasil angket variabel $\mathrm{X} 2$ menunjukan bahwa peran kepala madrasah sebagai supervisor tidak mempengaruhi profesionalisme guru

3. Berdasarkan hasil angket variabel $\mathrm{X} 1$ dan $\mathrm{X} 2$ menunjukan bahwa pengaruh peran kepala madrasah sebagai supervisor lebih dominan mempengaruhi profesionalisme guru MA Al Amiriyyah Blokagung Tegalsari Banyuwangi Tahun Pembelajaran 2019/2020.

Sehubungan dengan hasil penelitian dan kesimpulan yang dijelaskan diatas, dapat disampaikan beberapa saran kepada kepala madrasah sebagai berikut:

Pengaruh Peran Kepala Madrasah Sebagai Manajer dan Supervisor Terhadap Profesionalisme Guru MA Al Amiriyyah Blokagung Banyuwangi

Komarudin A., Vivi Indah Lestari 
JMPID ( Jurnal Manajemen Pendidikan Islam Darussalam )

Jurnal Manajemen Pendidikan Islam

1. Mengupayakan peningkatkan profesionalisme guru secara terus menerus dan berkelanjutan

2. Kepala madrasah untuk memaksimalkan program supervisi dalam meningkatkan profesionalisme guru

\section{F. Daftar Pustaka}

Hamalik, Oemar. 2006. Pendidikan Guru Berdasarkan Pendekatan Kompetensi. Jakarta. Bumi Aksara.

Karwati, Euis \& Donni Juni Priansa. 2015. Manajemen Kelas. Bandung. Alfabeta.

Maulida, Annisa. 2016. Peran kepala sekolah sebagai manajer dalam meningkatkan profesionalisme guru PAI di SMP IT Nur Hidayah Surakarta Tahun pembelajaran 2016/207. Skripsi tidak diterbitkan. Surakarta. Ilmu Tarbiyah dan Keguruan IAIN Surakarta.

Mulyasa, E. 2005. Menjadi Kepala Sekolah Profesional. Bandung. PT. Remaja Rosdakarya.

Mulyasa, E. 2008. Standar Kompetensi dan Sertifikasi Guru. Bandung. PT. Remaja Rosda Karya.

Mulyasa. 2017. Manajemen Berbasis Sekolah. Bandung. PT Remaja Rosdakarya.

Peraturan Menteri Pendidikan Nasional Nomor 13 Tahun 2007. Tentang Standar Kepala Sekolah.

Peraturan Menteri Pendidikan Nasional Nomor 28 Tahun 2010. Tentang Guru ditugaskan menjadi Kepala Sekolah/Madrasah.

Permendiknas Nomor 19 Tahun 2017. Tentang. Tentang Tugas Poko Kepala Madrsah/sekolah.

Priansa, Donni Juni \& Sonny Suntani Setiana. 2018. Manajemen \& Supervisi Pendidikan. Bandung. Cv. Pustaka Setia.

Riduwan. 2015. Pengantar Statistika. Bandung. Alfabeta.

Setiadi, Tawakal. 2013. Pengaruh kepala sekolah sebagai pendidik, manajer, motivator, dan supervisor terhadap kinerja guru di SMK

Pengaruh Peran Kepala Madrasah Sebagai Manajer dan Supervisor Terhadap Profesionalisme Guru MA Al Amiriyyah Blokagung Banyuwangi

Komarudin A., Vivi Indah Lestari 
JMPID ( Jurnal Manajemen Pendidikan Islam Darussalam )

Jurnal Manajemen Pendidikan Islam

Volume: 2, No: 2, September 2020

ISSN : 2722-7146 (online)

Piri 1 Yogyakarta. Skripsi tidak diterbitkan. Yogyakarta. Teknik Universitas Negeri Yogyakarta.

Sugiyono. 2017. Metode Penelitian Pendidikan. Bandung. Alfabeta.

Undang-Undang RI Nomor 14 Tahun 2005. Tentang Guru dan Dosen.

Wahyudin, Din. 2014. Manajemen Kurikulum. Bandung. PT Remaja Rosdakarya.

Pengaruh Peran Kepala Madrasah Sebagai Manajer dan Supervisor Terhadap Profesionalisme Guru MA Al Amiriyyah Blokagung Banyuwangi

Komarudin A., Vivi Indah Lestari 